\title{
An Approach for Micropropagation of Blueberry (Vaccinium corymbosum L.) Plants Mediated by Temporary Immersion Bioreactors (TIBs)
}

\author{
Ariel D. Arencibia, Carolina Vergara, Karla Quiroz, Basilio Carrasco, \\ Carmen Bravo, Rolando Garcia-Gonzales
}

Faculty of Agricultural and Forestry Sciences, Catholic University of Maule, Talca, Chile.

Email: arielarencibia@yahoo.com

Received March $13^{\text {th }}, 2013$; revised April 25 $5^{\text {th }}, 2013$; accepted May 10 $0^{\text {th }}, 2013$

Copyright (C) 2013 Ariel D. Arencibia et al. This is an open access article distributed under the Creative Commons Attribution License, which permits unrestricted use, distribution, and reproduction in any medium, provided the original work is properly cited.

\begin{abstract}
A new procedure for blueberry (Vaccinium corymbosum L.) micropropagation in programmed Temporary Immersion Bioreactors (TIBs based on two separate bottles) was developed for the commercial genotypes Biloxi, Sharp Blue and Brillita. Plant cultures were developed in a controlled environment with $0.4 \mathrm{MPa} \mathrm{CO}_{2}$ enrichment, sucrose-reduced medium, and light intensity of $60 \mu \mathrm{M} \mathrm{m}^{-2} \cdot \mathrm{s}^{-1}$. Principal component analysis showed that component $1(\mathrm{C} 1)$ grouped $64.08 \%$ of the total variability, while the first two components accounted for $86.97 \%$. Representation of the principal components demonstrated three clusters corresponding with the blueberry genotypes, and within each cluster plants micropropagated in agar-base medium grouped separately from those plants multiplied in TIBs. Both plant number and total internodes traits (related to the productive efficiency) were demonstrated superior in blueberries propagated in TIBs. Additionally, when transferred to greenhouse conditions, blueberries propagated in TIBs showed higher adaptability and growing rates than those cultured by the conventional approach, altogether evidencing the occurrence of a photomixotrophic stage in the vitroplantlets cultured in TIBs.
\end{abstract}

Keywords: Temporary Immersion Bioreactors; Vaccinium corymbosum L.; Photomixotrophic; Blueberry; Micropropagation

\section{Introduction}

The blueberry (Vaccinium corymbosum L.) a tetraploid perennial, rhizomatous, cross-pollinated shrub [1], is a commercially important crop worldwide, and Chile is one of the main producers and exporting countries [2]. The high content of antioxidant phenolic compounds, anthocyanins, flavonoids, and phenolic acids [3] confers to blueberries both great health maintenance benefits and potential therapeutic values $[4,5]$.

Conventional blueberry propagation through stem or rhizome cuttings is a relatively easy task. Nevertheless, tissue culture propagation has been established in order to reach genetic uniformity in the planting materials and to overcome problems: a) the variations in fruit characteristics originating from diminution in fruit yields [6], and b) the precocity of flowering, which delays the establishment of plantings [7]. Thus, conventional micropropagation of $V$. angustifolium based in gelled medium has been established and reported [8-11].

In addition, bioreactor technology has been introduced for mass propagation in different plant species [12-17]. In the case of lowbush blueberry (V. angustifolium Ait.), a protocol using RITA $^{\circledR}$ bioreactors combined with semisolid gelled medium has been developed for the cultivar Fundy and for two wild clones [18]. Because the high production costs render conventional micropropagation systems (agar-based) less suitable for large-scale production, liquid cultures and automation has the potential to resolve the manual handling of the various stages of micropropagation [15]. Bioreactor cultures also permit an additional management of both physical and chemical environments, such as air exchange, photosynthetic photon flux, and $\mathrm{CO}_{2}$ content, resulting in more efficient plant performance during the in vitro micropropagation [19-21].

The effects of natural ventilation on leaf ultrastructure of plants cultured in vitro demonstrated that characteris- 
tics, such as the epidermal cell walls, cytoplasm and, thylakoid stacking and distribution were similar to those of plants from in vivo conditions [22]. It was previously stated that leafy or chlorophyllous explants of a number of in vitro plant species had high photosynthetic ability while their growth and development occurred on sugarree medium rather than on sugar-containing medium, evidencing that environmental factors, such as $\mathrm{CO}_{2}$ concentration, light intensity, and relative humidity, promoted photosynthesis and transpiration of explants/hoots/ lantlets in vitro [23].

In the present study, for the first time, blueberry micropropagation was established in TIBs (two separate transparent containers). Bioreactors were standardized under high photon flux and $\mathrm{CO}_{2}$-rich environment. Data confirmed the TIBs plasticity as an integrative tool toward a high-scale production of blueberry plants.

\section{Materials and Methods}

\subsection{Plant Materials}

Stocks of blueberry plantlets of the genotypes Biloxi, Sharp Blue and Brillita were established in vitro following the method of Debnath [17]. Essentially, shoot tips $(\sim 5 \mathrm{~cm})$ were surface disinfected in a $10 \%$ commercial solution $\mathrm{NaOCl}$ plus $0.1 \%$ Tween 20 (15 min.) followed by a treatment in $70 \%$ ethanol $(5 \mathrm{~min}$.) and then three rinses in sterile distilled water. Shoot tips were cultured for 8 weeks in McCown's Woody Plant (WP) medium [24]. Culture medium was solidified with $8 \mathrm{gr} / \mathrm{l}$ agar and the $\mathrm{pH}$ was adjusted to 5.2 before autoclaving at $121^{\circ} \mathrm{C}$. Both sucrose and N6-[2-isopentenyl] adenine (2iP) were supplemented as the genotype requirement: Biloxi (35 $\mathrm{gr} / 1$ sucrose, $2 \mathrm{mg} / 1$ 2iP); Sharp Blue (30 gr/l sucrose, 3 $\mathrm{mg} / \mathrm{l}$ 2iP); Brillita (35 gr/l sucrose, $3 \mathrm{mg} / \mathrm{l}$ 2iP). Plant cultures were maintained at $23^{\circ} \mathrm{C} \pm 2^{\circ} \mathrm{C}$, for a $16 \mathrm{~h}$ photoperiod under a combination of both natural light and cool-white fluorescent tubes at a light intensity of $60 \mu \mathrm{M}$ $\mathrm{m}^{-2} \cdot \mathrm{s}^{-1}$.

\subsection{Establishment of Bioreactor Cultures}

Two-vessel bioreactors were set up following established designs [25-27]. A total of 10 internodes (2 buds) from vigorous blueberry plants of 20 days old (after subculture) were transferred to a sterile transparent bottle $(1 \mathrm{~L}$ capacity). The couple bottle contained $250 \mathrm{ml}$ of the same culture medium, but liquid, as above described per each genotype. The experimental factors were the following: a) Genotype (Biloxi; Sharp Blue; Brillita); b) Sucrose concentration in TIBs $(35 \mathrm{gr} / 1$ or $30 \mathrm{gr} / 1$ depending on genotype; $20 \mathrm{gr} / 1)$; c) Immersion frequency ( 3 min each $8 \mathrm{~h}$; 3 min. each 6 h); d) In vitro multiplication approach (TIBs; agar-base + sucrose as previously described in plant ma- terials); e) Explants management (internodes with leaves; internodes without leaves). Air quality in the TIBs working station was improved with $0.4 \mathrm{MPa} \mathrm{CO}_{2}$, and bioreactors were maintained during 35 days at $23^{\circ} \mathrm{C} \pm 2{ }^{\circ} \mathrm{C}$ under a combination of both natural light and cool-white fluorescent tubes at a light intensity of $60 \mu \mathrm{M} \mathrm{m}^{-2} \cdot \mathrm{s}^{-1}$. The experiments were replicated three times.

\subsection{Acclimatization}

Blueberry plants multiplied using both TIBs and agarbase (control) approaches were carefully separated, washed in water and, planted in 128-cell plug trays (cell volume $25 \mathrm{~cm}^{3}$ ) containing a mixture of composted pine bark and zeolite $(2: 1)$. Trays were maintained in the greenhouse, and the relative humidity was gradually reduced: $90 \% \rightarrow$ $80 \% \rightarrow 70 \%$ in 10 day intervals. Luminosity was $100 \mu \mathrm{M}$ $\mathrm{m}^{-2} \cdot \mathrm{s}^{-1}$ under the natural photoperiod of January-February, latitude $35^{\circ} 30^{\prime}$-altitude $71^{\circ} 30^{\prime}$, locality of Talca, Chile.

\subsection{Data Collection and Statistical Analysis}

The following variables were considered after the micropropagation cycle (35 days): total number of internodes, plant size (height), number of internodes per plant, plant number (in vitro shooting). The adaptability rate was determined after 30 days of planting (acclimatization). Multivariate principal component classification analysis and discriminate analysis [28] were performed using the STATISTICA V.6 software package (STATSOFT, Inc., 2003). Variance was calculated for the micropropagation traits related to productivity and was compared between treatments using Bartlett's homogeneity of variances test.

\section{Results}

A new procedure for blueberry micropropagation in programmed bioreactors (TIBs based on two separate bottles) was developed for the commercial genotypes Biloxi, Sharp Blue and Brillita. For a statistical characterization of the micropropagation process, a principal component analysis was conducted, including data from both the in vitro and the acclimatization stages (Table 1). Component $1(\mathrm{C} 1)$ grouped $64.08 \%$ of the total variability, while the first two components accounted for $86.97 \%$.

Component 1 , on the $\mathrm{X}$-axis, was represented by the effects of genotypes $(\mathrm{G})$ with negative correlation with the in vitro approach (IA). In this case, results showed that variables including total internodes (TI), plant size (PS), number of internodes per plant (NIP), plant number (PN), and in vitro shooting (IS) interacted positively altogether supporting the micropropagation rate. The variables of growing rate (GR) and greenhouse adaptability were found to negatively interact in $\mathrm{C} 1$. 
Table 1. Multivariate classification analysis of blueberry (Vaccinium corymbosum L.) micropropagation in Temporary Immersion Bioreactors (TIBs).

\begin{tabular}{lccc}
\hline & C 1 & C 2 & C 3 \\
\hline Eigen value & 6.32 & 2.26 & 0.33 \\
\% total variance & 64.08 & 22.89 & 3.71 \\
\% cumulative & $\mathbf{6 4 . 0 8}$ & $\mathbf{8 6 . 9 7}$ & 90.68 \\
(TI) Total internodes & $\underline{0.80}$ & 0.22 & -0.09 \\
(PS) Plant size (height) & $\underline{0.51}$ & 0.21 & 0.32 \\
(NIP) No. internodes/plant & $\underline{0.61}$ & -0.13 & 0.08 \\
(PN) Plant number & $\underline{0.78}$ & -0.32 & 0.11 \\
(IS) In vitro shooting & $\underline{0.69}$ & -0.35 & 0.02 \\
(GA) Greenhouse adaptability & $\underline{-0.66}$ & 0.27 & 0.45 \\
(SC) Sucrose concentration & 0.40 & $\underline{0.65}$ & -0.51 \\
(GR) Growing rate (greenhouse) & $\underline{-0.65}$ & 0.32 & 0.04 \\
(EM) Explants management & -0.23 & 0.39 & 0.10 \\
(IF) Immersion frequency & 0.45 & $\underline{0.58}$ & 0.32 \\
(IA) In vitro approach & $\underline{-0.74}$ & $\underline{0.89}$ & -0.88 \\
(G) Genotype & & -0.30 & 0.09 \\
\hline
\end{tabular}

Component 2, contributing $22.89 \%$ of variability (Yaxis), was represented by the interrelation between the factors of in vitro approach (IA) and sucrose concentration (SC). The Immersion frequency also contributed to $\mathrm{C} 2$. In general, the factor of in vitro approach (IA) was represented in both $\mathrm{C} 1$ and $\mathrm{C} 2$ components, while the explants management (EM) had no significant contribution to the principal components.

Graphic representation of $\mathrm{C} 1-\mathrm{C} 2$ presents both unique and overlapping positions. The plot of the two principal components (Figure 1) demonstrated three clusters corresponding with the blueberry genotypes. Within each cluster, plants micropropagated in agar-base medium (conventional approach as control treatments) grouped separately from those plants multiplied in TIBs.

Below, the images in Figure 2 show the results on the establishment of a new approach for $V$. corymbosum (L.) micropropagation in TIBs. Blueberry plants grew and multiplied (Figures 2(A) and (B)) in a sucrose-reduced culture medium, with $\mathrm{CO}_{2}$-rich and high luminosity environment. As expected, explants cultured in conventional agar medium showed a sufficient plant development (growth), but the in vitro secondary shooting was low down (Figure 2(C)), diminishing the total number of internodes. For all Biloxi, Sharp Blue and Brillita genotypes, overall variables related to the micropropagation rate were demonstrated superior in TIBs cultures compared to those for plants propagated in agar-base medium (Table 2, Figure 2(D)).
After transfer to the greenhouse, both growing and adaptability were evaluated in the TIBs-micropropagated plants. Results showed that more than $97 \%$ of the blueberries propagated in TIBs had adapted and showed a higher growing rate in comparison with plants from agarbase cultures (Table 2; Figure 2(E)). As was predictable, control plants propagated in agar-based medium (35 or $30 \mathrm{gr} / \mathrm{L}$ sucrose, without $\mathrm{CO}_{2}$-rich air) demonstrated approximately eighty percent adaptability to greenhouse conditions. Results could be explained because the environmental conditions (reduced sucrose $20 \mathrm{gr} / \mathrm{L}, \mathrm{CO}_{2}$-rich air, and higher luminosity) during TIBs culture might be influencing plants toward a photomixotrophic stage, which possibly primes blueberry plants for the acclimatization step. To reach the highest adaptation rates of vitroplantlets, an accurate management of the environmental factors influencing the plant evapotranspiration should be also considered. In this case, enclosed in a high natural luminosity period, the humidity was reduced gradually in 10 day intervals during 30 days.

The statistical analysis of micropropagation traits related to productivity shows the large variances for blueberry plants multiplied through the agar-base approach (Table 2). The plant size variance was not significant between the in vitro approaches in the studied genotypes. Meanwhile the Bartlett's test showed significant heterogeneity $(\mathrm{P}<0.05)$ for the variables total plant number, total internodes and greenhouse adaptability. Summarizing, the higher results for traits linked to plant micro 
multiplied in $\mathrm{CO}_{2}$-rich TIBs propagation yields were demonstrated in blueberries

\section{Discussion}

For the first time, an efficient micropropagation system based in two-vessel TIBs has been carried out using three commercial blueberry genotypes. TIBs may be considered as a natural tissue-culture approach [29], and it has been a reliable tool in this research. The two-vessel TIBs (one holds the liquid medium and the other the cultures of the plants) proved to be a more flexible approach with

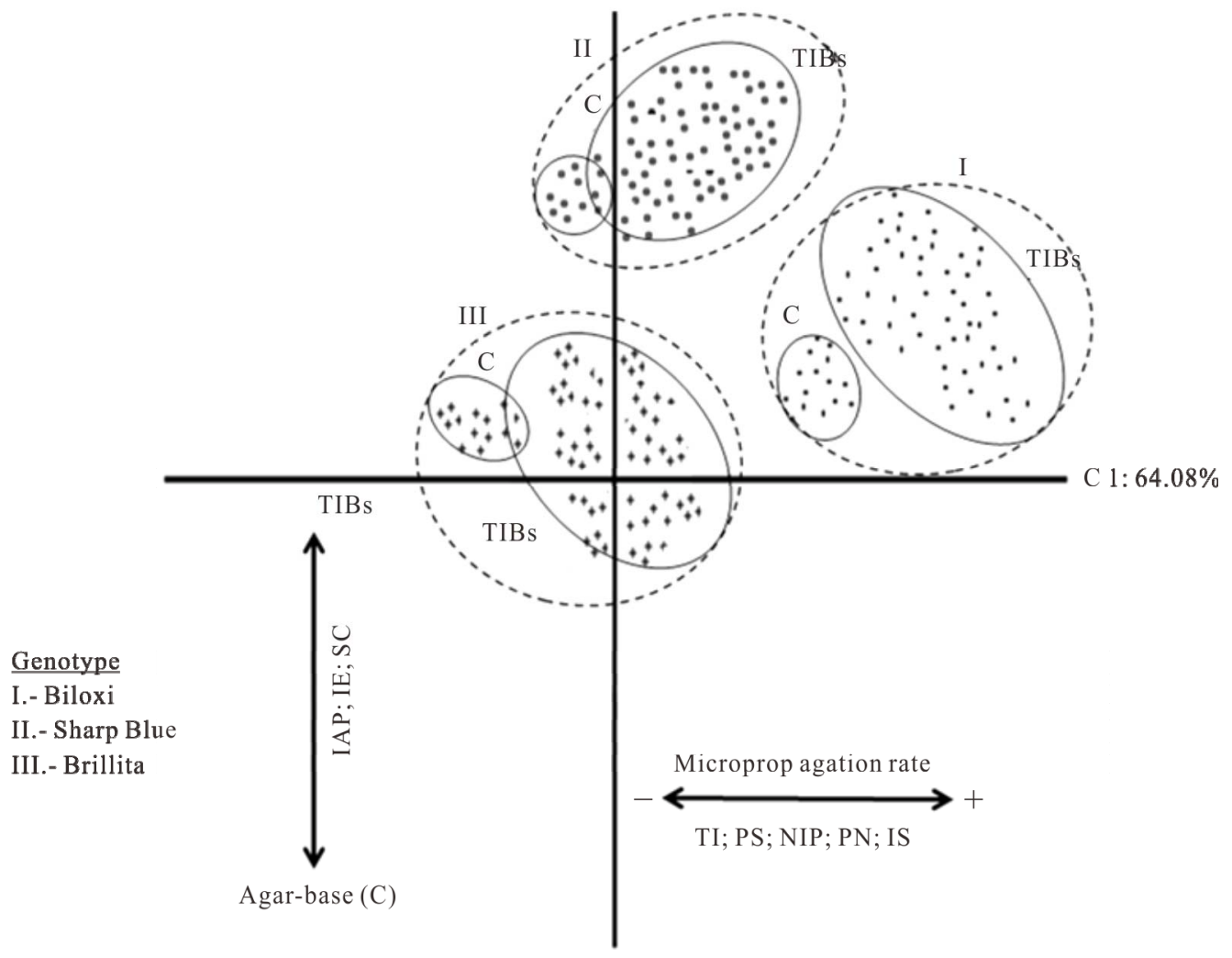

C2: $22.89 \%$

Figure 1. Graphic representation of the principal components analysis of blueberry (Vaccinium corymbosum L.) micropropagation in Temporary Immersion Bioreactors (TIBs). Conventional agar-base micropropagation was the control treatment for each genotype.

Table 2. Productive traits recorded during blueberry (Vaccinium corymbosum L.) micropropagation in $\mathrm{CO}_{2}$-rich TIBs and agar-base (control treatment). Both cultures were inoculated with 10 separate internodes per replica.

\begin{tabular}{|c|c|c|c|c|c|}
\hline Genotype & In vitro approach & Plant size $(\mathrm{cm})^{1}$ & Total plant number ${ }^{1}$ & Total internodes ${ }^{1}$ & $\begin{array}{c}\text { Greenhouse } \\
\text { adaptability }(\%)^{1}\end{array}$ \\
\hline \multirow{2}{*}{ Biloxi } & TIBs & $\begin{array}{c}8.6 \pm 1.7 \\
(0.36)\end{array}$ & $\begin{array}{l}22.6 \pm 4.6 \\
\quad(5.56)\end{array}$ & $\begin{array}{c}118.8 \pm 10.5 \\
(12.53)\end{array}$ & $\begin{array}{c}97.7 \pm 2.1 \\
(19.36)\end{array}$ \\
\hline & Agar & $\begin{array}{l}7.9 \pm 2.1 \\
(1.05)\end{array}$ & $\begin{array}{c}14.4 \pm 3.9 \\
(17.30)\end{array}$ & $\begin{array}{c}68.8( \pm 7.3) \\
(39.43)\end{array}$ & $\begin{array}{l}82.4 \pm 5.6 \\
(38.23)\end{array}$ \\
\hline \multirow{2}{*}{ Sharp Blue } & TIBs & $\begin{array}{c}7.2 \pm 2.2 \\
(0.67)\end{array}$ & $\begin{array}{l}26.2 \pm 6.6 \\
\quad(6.45)\end{array}$ & $\begin{array}{c}137.3 \pm 9.9 \\
(9.65)\end{array}$ & $\begin{array}{c}97.3 \pm 3.4 \\
(23.84)\end{array}$ \\
\hline & Agar & $\begin{array}{c}6.5 \pm 3.0 \\
(1.86)\end{array}$ & $\begin{array}{l}12.7 \pm 4.1 \\
(19.32)\end{array}$ & $\begin{array}{c}75.9 \pm 6.9 \\
(40.82)\end{array}$ & $\begin{array}{l}78.1 \pm 8.8 \\
(45.12)\end{array}$ \\
\hline \multirow{2}{*}{ Brillita } & TIBs & $\begin{array}{c}7.0 \pm 2.1 \\
(0.55)\end{array}$ & $\begin{array}{l}20.9 \pm 5.8 \\
(4.87)\end{array}$ & $\begin{array}{c}105.5 \pm 12.1 \\
(16.44)\end{array}$ & $\begin{array}{l}98.8 \pm 1.2 \\
(25.12)\end{array}$ \\
\hline & Agar & $\begin{array}{c}6.8 \pm 2.9 \\
(1.29)\end{array}$ & $\begin{array}{l}13.5 \pm 2.8 \\
(16.21)\end{array}$ & $\begin{array}{c}82.4 \pm 8.1 \\
(38.67)\end{array}$ & $\begin{array}{l}80.9 \pm 5.9 \\
(40.73)\end{array}$ \\
\hline Bartlett's test & & $2.72^{\mathrm{NS}}$ & $6.53^{*}$ & $19.68^{*}$ & $14.79^{*}$ \\
\hline
\end{tabular}

${ }^{1}$ Population mean and standard error (in brackets: variance). "Significant for $\mathrm{P}<0,05$ in the Bartlett's variance homogeneity test.

${ }^{\mathrm{NS}}$ Not significant in the Bartlett's variance homogeneity test. 

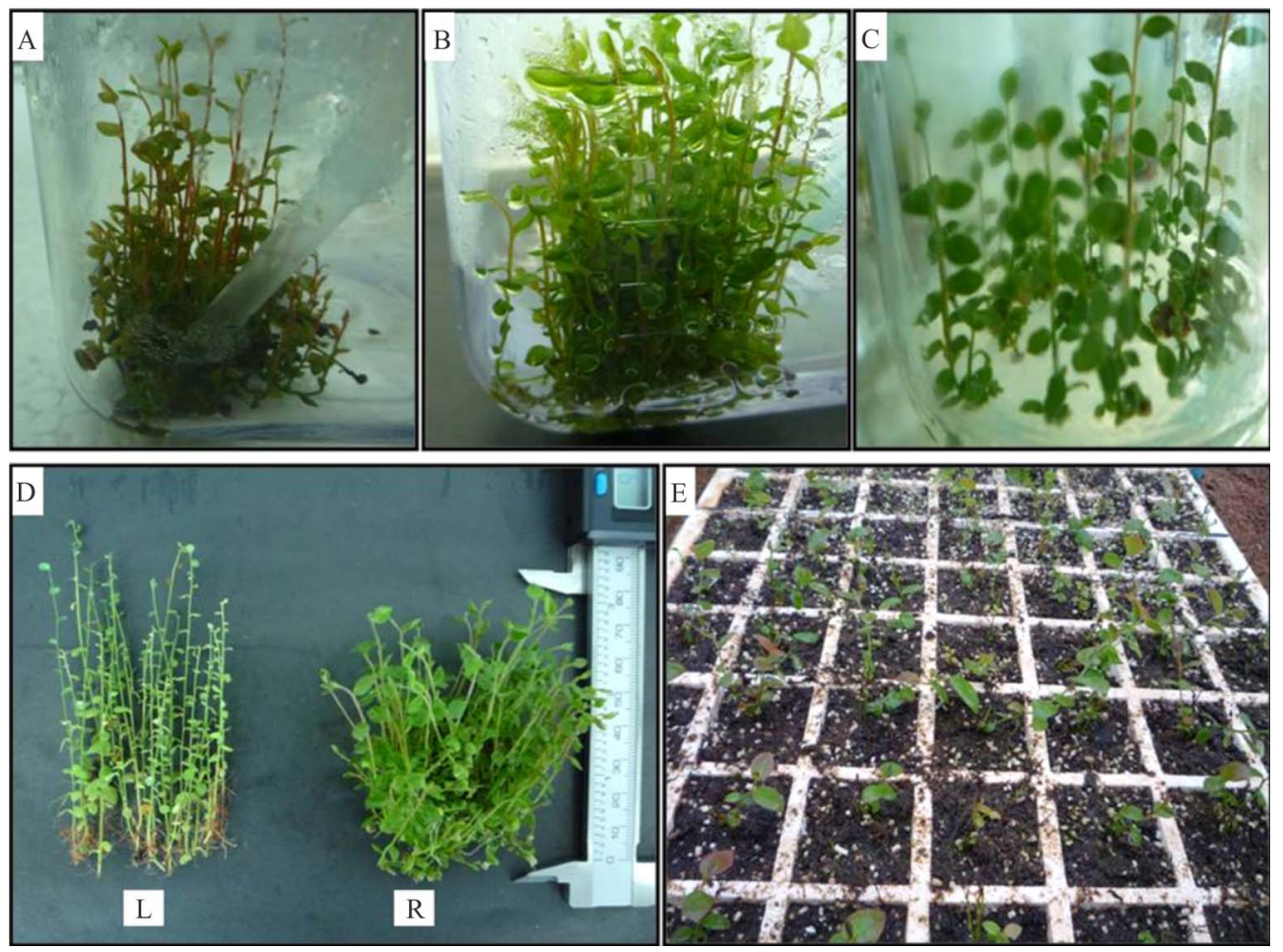

Figure 2. Micropropagation of blueberry (Vaccinium corymbosum L.) in bioreactors. (A) TIBs multiplying plants of $c v$. Biloxi after 25 days of culture; (B) plants of $c v$. Sharp Blue of 35 days of culture; (C) Control plants of $c v$. Sharp Blue growing in agar-base treatment (conventional); (D) Comparison of the propagation rates of blueberry plants (cv. Brillita) between conventional; (L) TIBs; (R) technologies; E. Micropropagated blueberry plants (cv. Biloxi) after 25 days of planting in greenhouse.

relatively simple construction and operational ease. Furthermore, TIBs might be optimized using a spectrum of glass/plastic containers and thus appropriate for largescale plant micropropagation facilities [30]. Previously Debnath [18] reported about lowbush blueberry micropropagation using RITA ${ }^{\circledR}$ bioreactors (VITROPIC, SaintMathieu-de-Treíviers, France; [31]), which could be considered as a more expensive alternative. The current TIBs involve much lower cost at the outset and perhaps less maintenance and supervisory cost during the propagation period as well.

Blueberry cultures in a controlled environment with $\mathrm{CO}_{2}$-enrichment, higher luminosity, and sucrose-reduced medium should be considered as a novel advance for micropropagation of shrub crops. Altogether, results demonstrate the plasticity of the TIBs technology to manage the major environmental factors toward an improvement of plant physiological processes, in this case the in vitro photosynthesis. Previously both the enhancement of the plant-air contact in a $0.4 \mathrm{MPa} \mathrm{CO}_{2}$ enrichment atmosphere and placement under a light intensity of 110 $\mathrm{mM} \mathrm{m} \mathrm{m}^{-2} \cdot \mathrm{s}^{-1}$ were significant factors to improve the phenolic metabolites secretion in sugarcane multiplication in TIBs [19]. The differential expression of Rubisco tran- scripts in increased $\mathrm{CO}_{2}$ concentration in parallel with a reduction of sucrose in the culture medium indicated the change from a heterotrophic to a photomixotrophic metabolic stage in vitro plantlets micropropagated in TIBs [21].

Blueberries propagated in TIBs showed higher adaptability and growing rates than those cultured by the conventional approach when plants were transferred to greenhouse conditions. This fact should be a measure of the occurrence of a photomixotrophic stage that enhances, or primes, the vitroplantlets cultured in TIBs. Priming of in vitro propagules refers to the manipulation of the growing environment, prior to and upon transplanting, and is an integral part of tissue culture propagation [32, 33]. The $\mathrm{CO}_{2}$ supply during the proliferation and multiplication stages in media with sucrose have been applied in bioreactors indicating increases in the plant growth during acclimatization and transplanting [29,34].

In the case of fruit trees, there are a few reports on this matter. The effects of different growth conditions (ventilated and closed vessels, medium with 0,15 , and $30 \mathrm{~g}$ $\mathrm{dm}^{-3}$ sucrose) during proliferation of quince (Cydonia oblonga Mill.) demonstrated a significant correlation between sucrose content in the leaves of donor shoots 
and the number of regenerated somatic embryos. This correlation suggests that identification of biochemical and physiological characteristics of donor shoots associated with increased regeneration ability might be helpful for improving morphogenesis in plant tissue culture [35].

In another example, Morini and Melai [36] studied the daily dynamics of $\mathrm{CO}_{2}$ concentration in the culture vessels and the photoautotrophic/photomixotrophic growth capacity of apple (Malus pumila hybrid MM106 paradisiaca $\times$ Northern Spy) under photon flux density of $210 \pm$ $5 \mu \mathrm{mol} \mathrm{m} \mathrm{m}^{-2} \cdot \mathrm{s}^{-1}$. They conclude that the photoautotrophic growth in the absence of sucrose was satisfactory, and the values of fresh and dry mass were equal to those obtained with sugar-enriched medium. Moreover, the induction of photoautotrophy also substantially improved the growth in cultures on sugar-enriched medium. Since in these experiments the photoperiod was shorter $(8 \mathrm{~h})$ than that normally used $(16 \mathrm{~h})$, they hypothesized that photoautotrophic growth should increase due to $\mathrm{CO}_{2}$ enrichment with the application of longer photoperiods.

In this paper, $\mathrm{CO}_{2}$ concentrations in TIBs were similar to those reported for sugarcane [19,21]; however, both sucrose reduction and luminosity were dissimilar according to the blueberry genotypes, and to the laboratory facilities, respectively. Considering photosynthesis as a complex process involving a range of environmental factors determining carbon assimilation, these results should be the tip of the iceberg toward further research on $V$. corymbosum (L.) micropropagation in TIBs, in this case as model specie of shrub crops.

For the first time, micropropagation of blueberries has been conducted in TIBs (two-bottles) under photomixotrophic conditions. An increase in both plant multiplication rate and total number of internodes has been demonstrated in three commercial genotypes. In parallel, efficient plant rooting and greenhouse adaptability has been obtained without growth regulator treatments (in vitro or ex vitro). Results pave the way for a further research to standardize micropropagation protocols to other woody plants and shrub crops.

\section{Acknowledgments}

We give thanks to Anne Bliss, Ph.D. (University of Colorado, USA) for the language revision and copyediting of the manuscript and the Regional Government of Maule (Chile) for financial support.

\section{REFERENCES}

[1] S. P. Vander Kloet, "The Genus Vaccinium in North America," Agriculture and Agri-Food Canada, Ottawa, 1988, p. 1828.

[2] ASOEX, "Chilean Exporters Association," 2011. http://www.asoex.cl

[3] W. Kalt, C. F. Forney, A. Martin and R. L. Prior, "Antioxidant Capacity, Vitamin C, Phenolics, and Anthocyanins after Fresh Storage of Small Fruits," Journal of Agricultural and Food Chemistry, Vol. 47, No. 11, 1999, pp. 4638-4644. doi:10.1021/jf990266t

[4] A. Cristoni and M. J. Magistretti, "Antiulcer and Healing Activities of Vaccinium mytrillus Anthiocyanosides," Farmaco Prat, Vol. 42, No. 2, 1987, pp. 29-43.

[5] H. Kamei, T. Kojima, M. Hasegawa, T. Koide, T. Umeda, T. Yukawa and K. Terabe, "Suppression of Tumor Cell Growth by Anthocyanins in Vitro," Cancer Investigation, Vol. 13, No. 6, 1995, pp. 590-594. doi:10.3109/07357909509024927

[6] A. R. Jamieson and N. L. Nickerson, "Field Performance of the Lowbush Blueberry Propagated by Seed, Stem Cuttings and Micropropagation," Acta Horticulturae, Vol. 626, 26th International Horticultural Congress on Berry Crop Breeding, Production and Utilization for a New Century, 2003, pp. 423-428.

[7] G. J. Galletta and J. R. Ballington, "Blueberries, Cranberries, and Lingonberries,” In: J. Janick and J. N. Moore, Eds., Fruit Breeding, Vol. 2, Vine and Small Fruit Crops, John Wiley \& Sons, Inc., New York, 1996, pp. 1-107.

[8] Nickerson NL (1978) In vitro shoot formation in lowbush blueberry seedling explants. Hort-Science 13: 698.

[9] J. J. Frett and J. M. Smagula, "In Vitro Shoot Production of Lowbush Blueberry," Canadian Journal of Plant Science, Vol. 63, No. 2, 1983, pp. 467-472. doi:10.4141/cjps83-054

[10] L. Brissette, L. Tremblay and D. Lord, "Micropropagation of Lowbush Blueberry from Mature Field-Grown Plants,' HortScience, Vol. 25, No. 3, 1990, pp. 349-351.

[11] Debnath SC (2004) In vitro culture of lowbush blueberry (Vaccinium angustifolium Ait.). Small Fruits Rev. 3: 393408. doi:10.1300/J301v03n03 16

[12] J. C. Lorenzo, B. L. Gonzalez, M. Escalona, C. Teisson, P. Espinosa and C. Borroto, "Sugarcane Shoots Formation in an Improved Temporary Immersion System," Plant Cell, Tissue and Organ Culture, Vol. 54, No. 3, 1998, pp. 197-200. doi:10.1023/A:1006168700556

[13] M. Escalona, G. Samson, C. Borroto and Y. Desjardins "Physiology of Effects of Temporary Immersion Bioreactors on Micropropagated Pineapple Plantlets," In Vitro Cellular and Developmental Biology Plant, Vol. 39, No. 6, 2003, pp. 651-656. doi:10.1079/IVP2003473

[14] Y. Ibaraki and K. Kurata, "Automation of Somatic Embryo Production," Plant Cell Tissue and Organ Culture, Vol. 65, No. 3, 2001, pp. 179-199. doi:10.1023/A:1010636525315

[15] K. Y. Paek, D. Chakrabarty and E. J. Hahn, “Application of Bioreactor Systems for Large Scale Production of Horticultural and Medicinal Plants," Plant Cell Tissue and Organ Culture, Vol. 81, 2005, pp. 287-300. doi:10.1007/s11240-004-6648-z

[16] X. C. Piao, D. Chakrabarty, E. J. Hahn and K. Y. Paek, "A Simple Method for Mass Production of Potato 
Microtubers Using a Bioreactor System," Current Science, Vol. 84, No. 8, 2003, pp. 1129-1132.

[17] D. Chakrabarty, E. J. Hahn, Y. S. Yoon and K. Y. Paek, "Micropropagation of Apple Root Stock 'M9 EMLA' Using Bioreactor," The Journal of Horticultural Science and Biotechnology, Vol. 78, No. 5, 2003, pp. 605-609.

[18] S. C. Debnath, "A Scale-Up System for Lowbush Blueberry Micropropagation Using a Bioreactor," HortScience, Vol. 44, No. 7, 2009), pp. 1962-1966.

[19] A. D. Arencibia, A. Bernal, L. Yang, L. Cortegaza, E. R. Carmona, A. Pérez, C. J. Hu, Y. R. Li, C. M. Zayas and I. Santana, "New Role of Phenylpropanoid Compounds during Sugarcane Micropropagation in Temporary Immersion Bioreactors (TIBs)," Plant Sciences, Vol. 175, No. 4, 2008, pp. 487-496. doi:10.1016/j.plantsci.2008.05.024

[20] A. Bernal, P. Machado, E. R. Carmona, O. Rivero, L. Cortegaza, M. Cabrera, C. M. Zayas, O. Nodarse, I. Santana and A. D. Arencibia, "Priming and Biopriming Integrated into the Sugarcane Micropropagation Technology by Temporary Immersion Bioreactors (TIBs)," Sugar Technology, Vol. 10, No. 1, 2008, pp. 42-47.

[21] Y. Liu, Y. Zambrano, C. J. Hu, E. R. Carmona, A. Bernal, A. Pérez, Y. R. Li, A. Guerra, I. Santana and A. D. Arencibia, "Sugarcane Metabolites Produced in $\mathrm{CO}_{2}$-Rich Temporary Immersion Bioreactors (TIBs) Induce Tomato (Solanum lycopersicum) Resistance against Bacterial Wilt (Ralstonia solanacearum)," In Vitro Cell Development Plant, Vol. 46, No. 6, 2010, pp. 558- 568.

[22] J. P. Majada, M. A. Fal, F. Tadeo and R. Sánchez, "Effects of Natural Ventilation on Leaf Ultrastructure of Dianthus caryophyllus L. Cultures in Vitro," In Vitro Cellular \& Developmental Biology: Plant, Vol. 38, No. 3, 2002, pp. 272-278. doi:10.1079/IVP2001271

[23] T. Kozai, C. Kubota and B. R. Jeong, "Environmental Control for the Large-Scale Production of Plants through in Vitro Techniques," Plant Cell, Tissue and Organ Culture, Vol. 51, No. 1, 1997, pp. 49-56. doi:10.1023/A:1005809518371

[24] G. Lloyd and B. McCown, "Commercially-Feasible Micropropagation of Mountain Laurel, Kalmia latifolia, by Use of Shoot-Tip Culture," Proceedings of the International Plant Propagators Society, Vol. 30, 1981, pp. 421-427.

[25] J. C. Lorenzo, M. A. Blanco, O. Pelaez, A. Gonzalez, M. Cid, A. Iglesias, B. Gonzalez, M. Escalona, P. Espinosa and C. Borroto, "Sugarcane Micropropagation and Phenolic Excretion," Plant Cell, Tissue and Organ Culture, Vol. 65, No. 1, 2001, pp. 1-8. doi:10.1023/A:1010666115337

[26] L. Yabor, P. Espinosa, J. C. Lorenzo and A. D. Arencibia, "Pineapple (Ananas comosus L. Merr.)," Methods in Mole- cular Biology, Vol. 344: 2007, pp. 219-226.

[27] N. Niemenak, K. S. Surminski, C. Rohsius, D. O. Ndoumou and R. Lieberei, "Regeneration of Somatic Embryos in Theobroma cacao L. in Temporary Immersion Bioreactor and Analyses of Free Amino Acids in Different Tissues," Plant Cell Reports, Vol. 27, No. 4, 2008, pp. 667-676. doi:10.1007/s00299-007-0497-2

[28] P. H. A. Sneath and R. R. Sokal, "Numerical Taxonomy: The Principles and Practice of Numerical Classification," San Francisco, 1973.

[29] J. Janick and M. Ziv, "Bioreactor Technology for Plant Micropropagation," Horticulture Review, Vol. 24, John Wiley \& Sons, Inc, New York, 2000, pp. 1- 30.

[30] H. Etienne and M. Berthouly, "Temporary Immersion Systems in Plant Micropropagation," Plant Cell, Tissue Organ Cultures, Vol. 69, No. 3, 2002, pp. 215-31. doi:10.1023/A:1015668610465

[31] C. Teisson and D. Alvard, "A New Concept of Plant in Vitro Cultivation Liquid Medium: Temporary Immersion," In: M.Terzi, R. Cella and A. Falavigna, Eds., Current Plant Science and Biotechnology in Agriculture. Vol. 22. Kluwer Academic Publication, Dordrecht, 1995, pp. 105110.

[32] U. Conrath, G. J. M. Beckers, V. Flors, P. García-Agustín, G. Jakab and F. Mauch, "Priming: Getting Ready for Battle," Molecular Plant-Microbe Interactions, Vol. 19, No. 10, 2006, pp. 1062-1071. doi:10.1094/MPMI-19-1062

[33] T. J. Bruce, M. C. Matthes, J. A. Napier and J. Pickett, "Stressful 'Memories' of Plants: Evidence and Possible Mechanisms," Plant Science, Vol. 173, No. 6, 2007, pp. 603-608. doi:10.1016/j.plantsci.2007.09.002

[34] T. Kozai, R. Jeong, C. Kubota and Y. Murai, "Effects of Volume and Initial Strength of Medium on the Growth, Photosynthesis and Ion Uptake of Potato (Solanum tuberosum L.) Plantlet in Vitro," Journal of the Japanese Society for Horticultural Science, Vol. 64, No. 1, 1995, pp. 63-71. doi: $10.2503 /$ jjshs.64.63

[35] M. Mingozzi, S. Morini, M. Lucchesini and A. Mensuali, "Effects of Leaf Soluble Sugars Content and Net PhoTosynthetic Rate of Quince Donor Shoots on Subsequent Morphogenesis in Leaf Explants," Biologia Plantarum, Vol. 55, No. 2, 2011, pp. 237-242. doi:10.1007/s10535-011-0034-6

[36] S. Morini and A. Melai, " $\mathrm{CO}_{2}$ Dynamics and Growth in Photoautotrophic and Photomixotrophic Apple Cultures," Biologia Plantarum, Vol. 47, No. 2, 2004, pp. 167-172. doi:10.1023/B:BIOP.0000022246.09161.63 